\title{
Continental Earthquakes: Physics, Simulation, and Data Science-Introduction
}

\author{
Zhongliang Wu, ${ }^{1}$ YongXian Zhang, ${ }^{1}$ Thomas H. W. Goebel, ${ }^{2}$ Qinghua Huang, ${ }^{3}$ Charles A. Williams, ${ }^{4}$ \\ Huilin Xing, ${ }^{5}$ and John B. RundLE ${ }^{6}$
}

\begin{abstract}
During May 12-14, 2018, the International Conference for the Decade Memory of the Wenchuan Earthquake, in connection to the 4th International Conference on Continental Earthquakes (4th ICCE) and the 12th General Assembly of the Asian Seismological Commission (ASC), was held in Chengdu, China. There have been several outcomes of the Conference (for example, the book published jointly by Higher Education Press and Springer) as well as the present special issue. Among the 58 submissions, 34 have been accepted after peer review. Some of the papers came from the presentations during the Conference, but with additional submissions, the scope of this special issue is far beyond that of the proceedings of the meeting.
\end{abstract}

\section{Study of the Wenchuan Earthquake and Its Sequence}

The study of continental earthquakes is difficult because the related geodynamic model has not been well developed. To overcome this difficulty, case studies of the phenomenology of continental earthquakes play an important role. It is not surprising, therefore, that although there have been so many works on the Wenchuan earthquake as well as its aftermath (see, e.g., http://www.isc.ac.uk/cgi-bin/ FormatBibprint.pl?evid=13228121), the Wenchuan earthquake, as one of the most destructive continental

\footnotetext{
1 Institute of Earthquake Forecasting, CEA, Beijing, China. E-mail:wuzhl@ucas.ac.cn; yxzhseis@sina.com

2 University of Memphis, Memphis, USA. E-mail: thgoebel@memphis.edu

3 Peking University, Beijing, China. E-mail: huangq@pku.edu.cn

4 GNS Science, Lower Hutt, New Zealand. E-mail: c.williams@gns.cri.nz

5 Ocean University of China, Qingdao, China. University of Queensland, Brisbane, Australia. E-mail: h.xing@uq.edu.au

6 UC Davis, Davis, USA. E-mail: john.b.rundle@gmail.com
}

earthquakes in the 21st century, continues to highlight the study of continental earthquakes.

The Wenchuan earthquake provides an important case for the study of short-term aftershock forecasting. Focusing on the comparison of the epidemic-type aftershock sequence (ETAS) model, the ReasenbergJones (R-J) model and the Omi-RJ model, which are widely adopted internationally for short-term aftershock forecasting, Bi and Jiang (2019) analyzed the Wenchuan aftershock sequence, compared the stability of model parameters, and evaluated the capability of aftershock rate forecasting. To adaptively forecast forthcoming large aftershocks of the Wenchuan earthquake, Chen et al. (2019) constructed a hazard model to describe the occurrence rate of aftershocks along the Longmenshan fault. The model, denoted by SRJ, is a combination of the ReasenbergJones (RJ) model and a spatial hazard model taking a reference of previous earthquakes in the study region. The rationale for considering spatial variations seems at least partly due to the spanning of the rupture of this great earthquake. In this sense the model is also heuristic for other great earthquakes which have size of earthquake rupture up to several $100 \mathrm{~km}$.

Analyzing the aftershocks of the Wenchuan earthquake, Matsushita et al. (2019) assessed the seismic potential around the northeastern edge of the Longmenshan fault zone (LFZ), focusing on the right-lateral strike-slip Qingchuan fault (QCF). The data used in the study were collected from a dense network of broadband seismographs installed after the Wenchuan mainshock. Analysis of the stress tensor revealed that the potential for a future earthquake in the QCF is high. To study the influences of the Wenchuan earthquake, Jiang et al. (2019b) constructed a three-dimensional viscoelastic finite element model of the crust, considering both the 
horizontal fragmentation and vertical strata of the crustal material in the Sichuan-Yunnan region, and the asymmetrical static displacement of hanging wall and footwall. Calculation of the Coulomb failure stress (CFS) indicated several regions with relatively higher seismic hazard after the Wenchuan earthquake, which will be tested in the near future.

Related to the stress variation associated with the preparation of the Wenchuan earthquake, Zhao et al. (2019) studied the $b$ value, which is regarded as closely related to the crustal stress. They used a total of 428,963 earthquakes from 1980 to 2013 after removal of the aftershock sequences and combined these data with the active fault distribution data to study the $b$ value changes before major earthquakes in western Sichuan. The results show that the $b$ values of the Fubianhe fault, Longmenshan main fault, and Shuangshi-Pengguan fault in western Sichuan decreased for at least 2 years before the major earthquakes. The $b$ values of the Longmenshan main fault area began to decrease slowly 5 years before the Wenchuan earthquake and sharply decreased in the year before the quake occurred. By analyzing the strong ground motion data of the 2008 Wenchuan and the 2013 Lushan earthquake, both located along the Longmenshan fault zone, Meng et al. (2019) pointed out that the high-frequency ground motion is controlled by stress changes in the rupture zone that give rise to the radiated ground acceleration. The apparent stresses for the Wenchuan and Lushan earthquakes are about 0.5 and $0.75 \mathrm{MPa}$, respectively, and the stress drops, in the same order, are about 2.5 and 3.5 MPa.

The phenomenology under investigation is not limited to seismic data. Yan et al. (2019) studied the response of vertical ionospheric electron density structure to the Wenchuan earthquake, recorded by the FORMOSAT-3/COSMIC (F3/C) radio occultation (RO) precise orbit determination (POD) total electron content (TEC). The horizontal propagation characteristics of the seismo-traveling ionospheric disturbances were identified by combining groundbased Global Navigation Satellite System (GNSS) TEC data and RO TEC data. The postseismic ionospheric infrasound wavefront with a wavelength of around $80 \mathrm{~km}$ at an altitude of $150-350 \mathrm{~km}$ was scanned vertically by an individual RO TEC profile.
A large amount of TEC profiles around the epicenter from 0000 to 1200 UT provide evidence of continental earthquake-induced vertical oscillations that lasted in the ionosphere for several hours. He and Singh (2019) analyzed water temperature data in continental China from the boreholes equipped with water temperature sensors, and found that nearly half of the boreholes show a coseismic response associated with the Wenchuan earthquake. They explained the mechanism of the coseismic groundwater temperature response with enhanced fluid flow induced by an earthquake. The groundwater temperature increases if the temperature sensor in the borehole is located near the deep-circulating aquifer, and decreases if the sensor is near the shallow-circulating aquifer when seismic waves arrive. The groundwater temperature may be slightly affected or even unchanged if the temperature sensor is far from the aquifer during the propagation of seismic waves. With local hydrological data and continuous GPS data in the nearby stations, Zhang et al. (2019) studied the gravity change near the epicenter of the Wenchuan $M_{w} 7.9$ earthquake. Their results showed that the absolute gravity change observed at the Pixian station did not match the calculation result caused by the groundwater level change and vertical deformation and related superficial reasons, which suggests that the pre-earthquake gravity increase may be caused by strain and mass (fluid) transfer in a broad seismogenic source.

The tremendous disaster caused by the Wenchuan earthquake reminds people of the importance of seismic disaster risk reduction. Wang et al. (2019) discussed the effective dissemination of earthquakerelated disaster risk reduction (DRR) knowledge to decision-makers and the public, and introduced the Disaster Risk Reduction Knowledge Service launched in 2016 by the International Knowledge Centre for Engineering Science and Technology (managed by the Chinese Academy of Engineering under the auspices of the UNESCO). In the Service the information related to the Wenchuan earthquake played an important role. Lang et al. (2019) compared the 2008 Wenchuan, Sichuan, $M_{S} 8.0$ earthquake and the 2014 Ludian, Yunnan, $M_{S} 6.5$ earthquake, both being continental earthquakes and causing unexpected losses. They calculated the losses per unit energy release 
per area. Not surprisingly, the Wenchuan earthquake caused more losses than the Ludian earthquake, but somewhat surprisingly, the latter had relatively higher losses per unit energy. They thus suggested that disaster mitigation policies in all regions are necessary, regardless of the degree of anticipated hazard.

\section{Other Regions, and Other Phenomena Subject to Discussion}

Studies of the reduction of seismic disaster risk also deal with other regions, both intraplate and interplate. Haque et al. (2019) evaluated the existing intensity attenuation model for the potential seismotectonic regimes in and around Bangladesh. In the paper, different magnitude types have been made uniform by converting into moment magnitude and subsequently into the Modified Mercalli Intensity (MMI) using the empirical relations developed in other places. Results and uncertainties of the work highlight the importance of comparative studies among different regions. In the work of Ghosh (2019), seismicity parameters including $b$-value, fractal dimension, energy release and recurrence period were assessed for the region $80^{\circ} \mathrm{E}-89^{\circ} \mathrm{E}, 26^{\circ}$ $\mathrm{N}-31^{\circ} \mathrm{N}$, providing clues to the seismogenesis of the 2015 Nepal $M_{\mathrm{W}} 7.8$ earthquake in central Himalaya. Tuluka et al. (2019) applied an improved probabilistic seismic hazard assessment to the Democratic Republic of Congo (DRC) and surrounding areas. The DRC 'encompasses both intra-plate and active tectonic areas associated with the Congo Craton and the western branch of the East African Rift System, respectively'.

The East Kunlun Fault (EKF) is one of the largest and most active sinistral strike-slip faults in the Tibetan Plateau. Since 1900, several major earthquakes have occurred in this region. The MaqinMaqu Segment (MMS), a seismic gap underlying a densely populated zone, is particularly important. Zhu et al. (2019) combined multiple sets of GPS and leveling observations to obtain the spatial-temporal distribution of locking segments along the EKF. Then they delineated the probable asperities based on the locations of locking segments and small earthquakes.
Combining the distribution of historical earthquakes, they concluded that the MMS is one of the high-risk zones for destructive earthquakes. Hou et al. (2019) improved a seismicity simulation program based on the Coulomb-Navier failure criterion and stress transfer mechanism to increase computational efficiency. The model was applied to the Taiyuan region of North China. The frequency-magnitude distribution of the simulation results fit well with the real earthquake catalogue, which tends to follow the characteristic earthquake model instead of the Gutenberg-Richter scaling relation. They found that a single fault region with a higher slip rate has lower $b$ values.

Earthquake case studies continue to provide rich learning experiences. Xu et al. (2019) studied the observed ground-motion intensity for six earthquakes of $M_{W}$ 6.0-6.2 occurring in China's North-South Seismic Zone (NSSZ), emphasizing the impact of source effects and paths of seismic wave propagation on the regional variability in observed ground-motion amplitude. They proposed that stress drop is an important component of source effects and should be considered in the functional form of ground motion prediction equations. On November 25, 2016, the $M_{w}$ 6.6 Aketao earthquake occurred in Xinjiang, western China. Dong et al. (2019) used a combination of ascending Sentinel-1A, descending Sentinel-1B and ascending ALOS-2 PALSAR data to measure the coseismic deformation. The coseismic slip distribution was derived using the steepest descent method (SDM) based on a single-segment fault model using the three InSAR line-of-sight (LOS) observations as constraints. The slip distribution reveals two slip centers. Postseismic deformation time series 1.5 years after the earthquake were retrieved from 26 multi-temporal Sentinel-1 descending scenes. The postseismic deformation shows similar patterns to the coseismic deformation. The $M_{w} 7.8$ Kaikoura, North Canterbury, New Zealand, earthquake, which occurred on November 14, 2016 (local time), however, provides an alternative case. This earthquake was one of the most complex continental earthquakes ever documented and among the largest instrumentally recorded events in New Zealand history. Studying this earthquake, Su et al. (2019) precisely estimated the three-dimensional coseismic and postseismic 
displacements caused by this event from continuous global navigation satellite systems (GNSS) stations in New Zealand. The coseismic inversion results suggest that rupture occurred both on shallow crustal faults, and to some extent on the southern Hikurangi subduction interface. The postseismic slip not only significantly extended along the subduction interface, but also appeared on the Needles fault. The spatial distributions of the postseismic and the coseismic slip, although having similar directions, exhibit the significant difference that the slip located along the shallow crustal faults activated the coseismic deformation, while the slip located on the deep subduction interface controlled the postseismic deformation.

Related to the possible pre-earthquake processes observed, Marchetti et al. (2019) investigated the magnetic field and electron density recorded by the Swarm three-satellite constellation over the seismic region hit by the 2016-2017 Amatrice-Norcia (central Italy) seismic sequence. They found that, when disturbed periods of the geomagnetic conditions are properly taken into account, an increase in anomalies starting about 40 days before the beginning of the seismic sequence could be identified. In the work of $\mathrm{Yu}$ et al. (2019), the load/unload response ratio (LURR) method was used for the case of the $M 7.0$ Jiuzhaigou earthquake that occurred on August 8, 2017 in Sichuan Province. In this work, the LURR values were calculated by using Benioff strain of the small earthquakes within 100, 200, 300 and $500 \mathrm{~km}$ from the epicenter and 12 years prior to the main shock. The loading and unloading phases are determined by calculating the change of Coulomb failure stress caused by Earth tide in the tectonically preferred slip direction on the fault surface of the major event. Results show that the LURR values remain at a low level for years until 2014 when the LURR values increase to an anomalously high level. Meanwhile, the magnitude of the anomalies decreases with the distance from the epicenter, and becomes difficult to identify outside the 500-km radius. Liu et al. (2019) investigated the observational data from 20 geomagnetic observatories at longitudes of $130{ }^{\circ} \mathrm{E}$ to 150 ${ }^{\circ} \mathrm{E}$ between 2009 and 2012 in order to detect possible anomalous changes in the geomagnetic solar quiet daily (Sq) variation related to the 2011 Tohoku earthquake $\left(M_{w}\right.$ 9.0) that occurred on March 11,
2011, off the Pacific coast of Japan. They confirmed that about 1.5 months before the earthquake there were significant anomalous variations in the observation. These case studies provide earthquake forecast research with useful clues, keeping in mind that retrospective analysis of earthquake cases has its intrinsic limitation.

The case analysis also deals with other kinds of events. The catastrophic Sanyanyu and Luojiayu debris flows, which were induced by heavy rain, struck Zhouqu County in Gannan Prefecture, Gansu Province, China, at about midnight on August 7, 2010, causing 1765 fatalities and huge economic loss. The ZHQ seismic station is located some $170 \mathrm{~m}$ west of the outlet of the Sanyanyu gully, and its power system was destroyed by the Sanyanyu debris flow when its leading edge reached the vicinity of the seismic station. In the paper by Huang et al. (2019), seismic signals recorded by the ZHQ station approximately $10 \mathrm{~min}$ before its termination were collected and analyzed to characterize the Sanyanyu debris flow, providing a good case of seismic recordings applied to the monitoring of other kinds of disasters.

\section{Theoretical Discussion and Innovative Methods Proposed/Discussed}

As part of the development of innovative methods for seismic disaster risk assessment, Rundle et al. (2019) used the concept of nowcasting, referring to the use of proxy data to estimate the current dynamic state of driven complex systems such as earthquakes, neural networks, or financial markets. In the paper they extended the nowcasting method proposed in their previous work to great global earthquakes of magnitudes as large as $M 9$ by defining the surrounding large region as the entire Earth. The current hazard of a number of selected local regions were analyzed, and ranked in terms of current risk of great earthquakes. These great events also present significant hazards for generating mega-tsunamis. One of their main results is that the eastern Aleutian Islands, site of the $M 8.6$ earthquake of 1946, is currently the region most at current risk of a great earthquake larger than $M$ 8.0. Crespi et al. (2019) proposed an 
integrated approach to earthquake prediction based on the synergy of high-density geodetic observations and seismological information. They thus developed intermediate-term medium-range earthquake prediction which has been used for a long time in seismic hazard assessment into 'intermediate-term narrowrange earthquake prediction'. The extent of the alarmed areas, identified for strong earthquakes by earthquake prediction algorithms based on seismicity patterns, can be significantly reduced from linear dimensions of a few hundred to a few tens of kilometers. They applied the methodology to the 2016-2017 seismic crisis in central Italy and the 2012 Emilia sequence.

Related to the theoretical basis for the reduction of seismic disaster risk, Li et al. (2019) evaluated the presently proposed simple models for slip distribution, including the homogeneous slip model, the triangular slip model, the $k$-square model, the slip tip taper model, and the restricted stochastic source model, to investigate which is most consistent with 'real-world' slip distribution inversions. The 2011 Van (eastern Turkey) $M_{W} 7.1$ earthquake was taken as an example, considering six inversion results of slip distribution. The Akaike information criterion (AIC) was used to evaluate the models. The evaluation shows that for all the six inversion results, the $k$ square model seems most consistent with the 'realworld' slip distribution. The conclusion has apparent significance in the simulation of scenario earthquakes for seismic disaster resilience.

Techniques for earthquake monitoring and forecast have some new developments. A long-term study at the Petropavlovsk-Kamchatskii Geodynamical Test Site (Russia) provides the results of the continuous monitoring of the stress-strain state based on borehole geo-acoustic measurements and electromagnetic measurements with underground electric antennas (Gavrilov et al. 2019). Combined with hydro-geochemical and hydro-geodynamic borehole measurements, these methods allow monitoring the changes in the parameters of geological environment and identifying the changes of its stress-strain state. Rebetsky and Guo (2019) discussed the relation of tectonic stress and the nucleation of megaearthquakes. Jiang et al. (2019a) used the shifting correlation method to analyze 2-month recordings of
20 geoelectric stations in Taiwan and found that at least two stations had recorded geoelectric signals significantly correlated with known seismic events. These two stations are installed on large reverse faults, which are probably characterized by high stress concentrations before earthquakes. The analysis supports the viewpoint that lateral and vertical electrical resistivity variation and conductors in the subsurface may be able to amplify seismic electric signals.

Data processing is another focus of attention. In the paper of Ren et al. (2019), a machine learning model for accurate (with correctness ratio about 89\%) and quick classification of tectonic and nontectonic earthquakes was proposed and tested using the data of the Chinese national seismograph network. Bai et al. (2019) presented a new sampling scheme for seismic network observations and seismic exploration data acquisition based on compressive sensing theory. They perform a real data test and synthetic data tests to illustrate that the proposed method can be used stably to achieve compressive sampling and successful recovery of high resolution seismic waveform data. The accurate measurement of ultrasonic velocity requires the detected waveforms to have high signal-to-noise ratio (SNR). The coded excitation technique (CET) can improve the SNR without resolution loss. Wu et al. (2019) discussed the basic principles of phase-coded technology and conducted synthetic and experimental evaluations of two different CET implementations. Hao and Li (2019) compared the locations of 173 earthquakes (including the 2008 Wenchuan earthquake) using the Hotan seismic array data and those from the China Earthquake Network Center (CENC). By such comparison they identified a dipping layer beneath the array, which is useful for the 'structure-correction' of the seismic array processing. Filatov and Lyubushin (2019) applied a modified detrended fluctuation analysis (DFA) method to determine the quantitative measure of chaoticity, which is a use of fractal analysis of geophysical big data as a precursory method for the estimation of current seismic hazard. The case study of seismic hazard in the California region with time series of GPS land surface displacements is consistent with the canonical coherence analysis (CCA), which permits one 'to quantify the 
degree of synchronized behavior of constituents of the Earth's crust'.

\section{Discussion with (out) Conclusions}

It may be seen from the present special issue that although the theoretical framework for the genesis, preparation, occurrence, and aftermath of continental earthquakes is still to be established, the agenda for discussion is relatively clear. From the perspective of basic science, observation and modeling of the faulting, deformation, stressing, rheology, thermal, and related geophysical effects associated with continental earthquakes are the main problems. From the perspective of application, analysis and modeling of the destruction, losses, and secondary disasters caused by continental earthquakes are the main issues. Such an agenda for discussion could be regarded as being rooted in an important concept in the physics of complexity: emergence. Indeed, understanding molecules does not mean the understanding of life. Similarly, although at the present time we have good understandings of plate tectonics, fault systems, earthquake cycles, rupture processes, and the resistance of fracture, understanding of continental earthquakes as well as the social resilience against continental earthquake disasters still has a long way to go. The advice of Jack Oliver could be an important guidance for future work: Those who cultivate the ability to communicate with the Earth through observation will learn most about it. Apparently it also holds for continental earthquakes.

Many contributions are from Chinese authors, whose names sometimes make non-Chinese speakers confused. Traditionally Chinese have no middle name, and tend to use the family name first. But in some international circumstances they also follow the English convention to use family name last, and sometimes abbreviate first name into one or two single letter/s (sometimes using a dash in between). Even in this special issue these two different ways are followed in parallel, depending on different authors. In the reference list of this introduction we unified the expression of the names by introducing an empirical regularity: For the majority (but not all) of Chinese names, the first name is usually longer than the family name in pronunciation.

\section{Acknowledgements}

Organization of the publication got decisive help from Dr. Renata Dmowska, editor of special issues of $P A G E O P H$. The guest editors acknowledge with gratitude the efforts of numerous colleagues in different countries serving as referees. Especially the contribution of the APEC Cooperation for Earthquake Science (ACES), as well as its leaders, in the organization of the special issue, should be acknowledged. The editorial team thanks the organizers of the International Conference for the Decade Memory of the Wenchuan Earthquake in connection to the 4th ICCE and the 12th ASC GA, who initiated the present volume. The present special issue as well as its organization was supported by the China Seismic Experimental Site (CSES) which was also one of the outcomes of that International Conference.

Publisher's Note Springer Nature remains neutral with regard to jurisdictional claims in published maps and institutional affiliations.

\section{REFERENCES}

Bai, L. S., Lu, H. Y., \& Liu, Y. K. (2019). High-efficiency observations: compressive sensing and recovery of seismic waveform data. Pure and Applied Geophysics. https://doi.org/10. 1007/s00024-018-2070-z.

Bi, J. M., \& Jiang, C. S. (2019). Comparison of early aftershock forecasting for the 2008 Wenchuan $M_{\mathrm{s}} 8.0$ earthquake. Pure and Applied Geophysics. https://doi.org/10.1007/s00024-019-021926.

Chen, Y.-I., Liu, J.-Y., \& Lai, H.-W. (2019). Assessment of spacetime hazard of large aftershocks of the $2008 M_{\mathrm{w}} 7.9$ Wenchuan earthquake. Pure and Applied Geophysics. https://doi.org/10. 1007/s00024-019-02193-5.

Crespi, M., Kossobokov, V., Panza, G. F., \& Peresan, A. (2019). Space-time precursory features within ground velocities and seismicity in North-Central Italy. Pure and Applied Geophysics. https://doi.org/10.1007/s00024-019-02297-y.

Dong, Y. F., Meng, G. J., \& Hong, S. Y. (2019). Coseismic and postseismic deformation of the $2016 M_{\mathrm{w}} 6.6$ Aketao earthquake from InSAR observations and modeling. Pure and Applied Geophysics. https://doi.org/10.1007/s00024-019-02092-9. 
Filatov, D. M., \& Lyubushin, A. A. (2019). Precursory analysis of GPS time series for seismic hazard assessment. Pure and Applied Geophysics. https://doi.org/10.1007/s00024-018-2079-3.

Gavrilov, V. A., Panteleev, I. A., Deshcherevskii, A. V., Lander, A. V., Morozova, Yu V, Yu, Buss Yu., et al. (2019). Stress-strain state monitoring of the geological medium based on the multiinstrumental measurements in boreholes: experience of research at the Petropavlovsk-Kamchatskii Geodynamic Testing Site (Kamchatka, Russia). Pure and Applied Geophysics. https://doi. org/10.1007/s00024-019-02311-3.

Ghosh, U. (2019). Seismic characteristics and seismic hazard assessment: Source region of the 2015 Nepal earthquake $M_{\mathrm{w}} 7.8$ in central Himalaya. Pure and Applied Geophysics. https://doi. org/10.1007/s00024-019-02318-w.

Hao, C. Y., \& Li, L. (2019). Using a structure correction method to improve the location accuracy of the Hotan Seismic Array. Pure and Applied Geophysics. https://doi.org/10.1007/s00024-01902286-1.

Haque, D. M. E., Chowdhury, S. H., \& Khan, N. W. (2019). Intensity attenuation model evaluation for Bangladesh with respect to the surrounding potential seismotectonic regimes. Pure and Applied Geophysics. https://doi.org/10.1007/s00024-01902230-3.

He, A. H., \& Singh, R. P. (2019). Coseismic groundwater temperature response associated with the Wenchuan earthquake. Pure and Applied Geophysics. https://doi.org/10.1007/s00024019-02097-4.

Hou, Y., Jin, X., \& Zhou, S. Y. (2019). Update and test of a seismicity simulation program based on the Coulomb-Navier failure criterion and the stress transfer mechanism. Pure and Applied Geophysics. https://doi.org/10.1007/s00024-019-02261w.

Huang, X. H., Li, Z. Y., Fan, J. Y., Yu, D., \& Xu, Q. (2019). Frequency characteristics and numerical computation of seismic records. Pure and Applied Geophysics. https://doi.org/10.1007/ s00024-019-02177-5.

Jiang, F. Y., Chen, X. B., Chen, C.-C., \& Chen, H.-J. (2019a). Relationship between seismic electric signals and tectonics derived from dense geoelectric observations in Taiwan. Pure and Applied Geophysics. https://doi.org/10.1007/s00024-018-2077-5.

Jiang, F. Y., Ji, L. Y., \& Zhu, L. Y. (2019b). 3d viscoelastic finite element study of post-seismic influence of the Wenchuan earthquake in the Sichuan-Yunnan region. Pure and Applied Geophysics. https://doi.org/10.1007/s00024-019-02179-3.

Lang, C., Gao, M. T., Wu, X. Y., \& Wu, G. C. (2019). Continental earthquakes in China and loss implications: comparison of the 2014 Ludian $\mathrm{M}_{\mathrm{s}} 6.5$ and the 2008 Wenchuan $M_{\mathrm{s}} 8.0$ earthquakes 5:6. Pure and Applied Geophysics. https://doi.org/10.1007/ s00024-019-02115-5.

Li, J. W., Wu, Z. L., Jiang, C. S., Zhou, S. Y., \& Zhang, Y. (2019). Simple models of complex slip distribution? A case study of the $2011 M_{\mathrm{w}} 7.1$ Van (eastern Turkey) earthquake. Pure and Applied Geophysics. https://doi.org/10.1007/s00024-019-02167-7.

Liu, X. C., Hattori, K., Han, P., Chen, H. R., Chie, Y., \& Zhao, X. D. (2019). Possible anomalous changes in solar quiet-day geomagnetic variations (Sq) related to the 2011 off the Pacific coast of Tohoku earthquake $\left(M_{\mathrm{w}}\right.$ 9.0). Pure and Applied Geophysics. https://doi.org/10.1007/s00024-018-02086-z.

Marchetti, D., De Santis, A., D'Arcangelo, S., Poggio, F., Jin, S. G., Piscini, A., et al. (2019). Magnetic field and electron density anomalies from Swarm satellites preceding the major earthquakes of the 2016-2017 America-Norcia (Central Italy) seismic sequence. Pure and Applied Geophysics. https://doi.org/ 10.1007/s00024-019-02138-y.

Matsushita, R., Imanishi, K., Ohtani, M., Kuwahara, Y., Chen, J. H., \& Ma, S. L. (2019). Seismic potential around the northeastern edge of the Longmenshan fault zone as inferred from seismological observations. Pure and Applied Geophysics. https://doi. org/10.1007/s00024-019-02098-3.

Meng, L. Y., Zang, Y., McGarr, A., \& Zhou, L. Q. (2019). Highfrequency ground motion and source characteristics of the 2008 Wenchuan and 2013 Lushan, China, Earthquakes. Pure and Applied Geophysics. https://doi.org/10.1007/s00024-019-022914.

Rebetsky, Y. L., \& Guo, Y. S. (2019). From natural stresses in seismic zones to the prediction of the nucleation zones of megaearthquakes. Pure and Applied Geophysics. https://doi.org/ 10.1007/s00024-019-02128-0

Ren, T., Wang, P. Y., Lin, M. N., Liu, X. Y., Chen, H. F., \& Liu, J. (2019). Classification of tectonic and nontectonic earthquakes by an integrated learning algorithm. Pure and Applied Geophysics. https://doi.org/10.1007/s00024-019-02233-0.

Rundle, J. B., Luginbuhl, M., Khapikova, P., Turcotte, D. L., Donnellan, A., \& McKim, G. (2019). Nowcasting great global earthquake and tsunami sources. Pure and Applied Geophysics. https://doi.org/10.1007/s00024-018-2039-y.

Su, X. N., Meng, G. J., Su, L. N., Wu, W. W., \& Liu, T. (2019). Coseismic and early postseismic deformation of the $2016 M_{\mathrm{w}} 7.8$ Kaikōura earthquake, New Zealand from continuous GPS observations. Pure and Applied Geophysics. https://doi.org/10. 1007/s00024-019-02169-5.

Tuluka, G. M., Lukindula, J., \& Durrheim, R. J. (2019). Seismic hazard assessment of the Democratic Republic of Congo and environs based on the GEM-SSA catalogue and a new seismic source model. Pure and Applied Geophysics. https://doi.org/10. 1007/s00024-018-2084-6.

Wang, J. L., Bu, K., Yang, F., Yuan, Y. L., Wang, Y. J., Han, X. H., et al. (2019). Disaster risk reduction knowledge service: a paradigm shift from disaster data towards knowledge services. Pure and Applied Geophysics. https://doi.org/10.1007/s00024019-02229-w.

Wu, H.-Z., Zhu, W., He, T.-M., Liu, Z.-Y., \& Lan, X.-W. (2019). Application of coded excitation signals for measurement of rock ultrasonic wave velocity. Pure and Applied Geophysics. https:// doi.org/10.1007/s00024-019-02166-8.

Xu, P. B., Ren, Y. F., Wen, R. Z., \& Wang, H. W. (2019). Observations on regional variability in ground-motion amplitude from six $M_{\mathrm{w}} 6.0$ earthquakes of the north-south seismic zone in China. Pure and Applied Geophysics. https://doi.org/10.1007/ s00024-019-02176-6.

Yan, X. X., Yu, T., Sun, Y. Y., Xia, C. L., Zuo, X. M., Yang, N., et al. (2019). Vertical structure of the ionospheric response following the $M_{\mathrm{w}} 7.9$ Wenchuan earthquake on 12 May 2008. Pure and Applied Geophysics. https://doi.org/10.1007/s00024-01902175-7.

Yu, H. Z., Yu, C., Ma, Z., Zhang, X. T., Zhang, H., Yao, Q., et al. (2019). Temporal and spatial evolution of load/unload response ratio before the $M 7.0$ Jiuzhaigou earthquake occurred on Aug. 8, 2017 in Sichuan Provinc. Pure and Applied Geophysics. https:// doi.org/10.1007/s00024-019-02101-x.

Zhang, Y., Chen, S., Xing, L. L., Liu, M., \& He, Z. T. (2019). Gravity changes before and after the $2008 M_{\mathrm{w}} 7.9$ Wenchuan 
earthquake at Pixian absolute gravity station in more than a decade. Pure and Applied Geophysics. https://doi.org/10.1007/ s00024-019-02356-4.

Zhao, B. J., Yang, G. L., Wang, J. P., \& Dong, F. F. (2019). Research on $b$ values based on fault buffers. Pure and Applied Geophysics. https://doi.org/10.1007/s00024-019-02163-x.
Zhu, L. Y., Ji, L. Y., \& Jiang, F. Y. (2019). Variations in locking along the east Kunlun fault, Tibetan Plateau, China, using GPS and leveling data. Pure and Applied Geophysics. https://doi.org/ 10.1007/s00024-019-02231-2.

(Published online December 17, 2019) 